\title{
Fístula cutânea odontogênica: relato de um caso clínico após múltiplos diagnósticos errôneos
}

Jennifer Santos PEREIRA'; Carlos Vieira ANDRADEJÚNIOR'; Emmanuel J. N. L. SILVA ${ }^{3}$

1 - DDS - Departamento de Endodontia, Universidade Estadual do Sudoeste da Bahia (UESB); 2 - DDS, MSc, PhD - Departamento de Endodontia, Universidade Estadual do Sudoeste da Bahia (UESB); 3 - DDS, MSc, PhD - Departamento de Endodontia, Universidade do Estado do Rio de Janeiro (UERJ), Universidade do Grande Rio (UNIGRANRIO).

\section{Resumo}

A fístula cutânea de origem odontogênica é decorrente da infecção crônica e quando mal diagnosticada, por médicos e/ou cirurgiões-dentistas, pode ocasionar alteração estética e transtornos psicológicos ao paciente. O presente relato de caso descreve o correto diagnóstico e o tratamento de uma paciente que foi anteriormente encaminhada a diferentes profissionais de saúde, sendo inclusive submetida à biopsia após hipóteses diagnósticas incorretas. Após avaliação clínica e de exames radiográficos periapicais e tomografia computadorizada de feixe cônico, solicitados por um endodontista, o caso foi diagnosticado de maneira adequada e um plano de tratamento foi proposto. $\mathrm{O}$ tratamento endodôntico não cirúrgico foi realizado, proporcionando a resolução da fístula em curto período de tempo. O presente caso clínico reforça a necessidade de se realizar o diagnóstico diferencial de patologias associadas às fístulas cutâneas ocorridas na região facial ou cervical, e da importância da colaboração interprofissional, inclusive considerando a etiologia odontogênica.

PALAVRAS-CHAVE: Necrose da Polpa Dentária; Fístula cutânea; Diagnóstico. 


\section{Introdução}

Fístulas cutâneas odontogênicas são dermatoses, relativamente incomuns, que ocorrem por infecções crônicas de origem pulpar, fratura radicular, irritação química ou trauma dentário ${ }^{1}$. Essa infecção provoca um processo inflamatório osteoclástico local que lentamente desenvolve um abscesso ósseo, progredindo gradualmente através do osso alveolar e periósteo para o local de menor resistência ${ }^{2,3}$.

A drenagem da secreção purulenta, geralmente, ocorre a partir de uma abertura intraoral na área gengival (na mucosa alveolar, gengiva livre ou ligamento periodontal), ou a partir de uma abertura extraoral na pele 4 . Além disso, a drenagem extraoral depende da localização do dente afetado, bem como de fatores específicos como a virulência do microrganismo, a resistência do hospedeiro e a relação entre a anatomia e as inserções musculares faciais ${ }^{5}$.

O diagnóstico clínico de lesões cutâneas de origem odontogênica pode ser desafiador, já que, muitas vezes o aparecimento inicial é semelhante a de outras condições, como infecções de pele, furúnculos, pelos encravados ou ductos obstruídos das glândulas sudoríparas, osteomielite, neoplasias, tuberculose, actinomicose e carcinomas ${ }^{3,4,6}$. Nem sempre as lesões cutâneas surgem nas proximidades da infecção subjacente e nem sempre os pacientes associam a problemas dentários. O tratamento com antibióticos sistêmicos resulta na interrupção temporária da drenagem que retorna após o término do tratamento com antibióticos ${ }^{4}$.

Embora o diagnóstico de tal condição muitas vezes pode ser realizado de maneira errônea, quando corretamente diagnosticada essa condição apresenta grandes taxas de resolutividade. O tratamento endodôntico ou a extração dentária possibilitam a cicatrização e o desaparecimento das fístulas cutâneas entre 5 a 14 dias. Em geral, não é necessário tratar a cicatriz da lesão cutânea, exceto por motivos estéticos ${ }^{7}$. Diante do exposto, o presente estudo tem como objetivo relatar um caso clínico de fístula cutânea de origem odontogênica, ressaltando a importância do 
diagnóstico diferencial e da colaboração interprofissional para resolução do caso.

\section{Relato do caso}

O presente relato de caso teve aprovação pelo Comitê de Ética em Pesquisa da Universidade Estadual do Sudoeste da Bahia (UESB), sob parecer favorável: 4.656.122, CAAE: 45109321.9.0000.0055.

Paciente M.C.B.S, leucoderma, sexo feminino, 39 anos de idade, foi referenciada a uma clínica particular do munícipio de JequiéBA, por um cirurgião-dentista para avaliação endodôntica. A paciente relatou que procurou atendimento odontológico após odontalgia e dentro de pouco tempo houve desenvolvimento de um aumento de volume sem presença de fístula (Figura 1A), evoluindo para um nódulo com superfície crostosa não cicatrizante
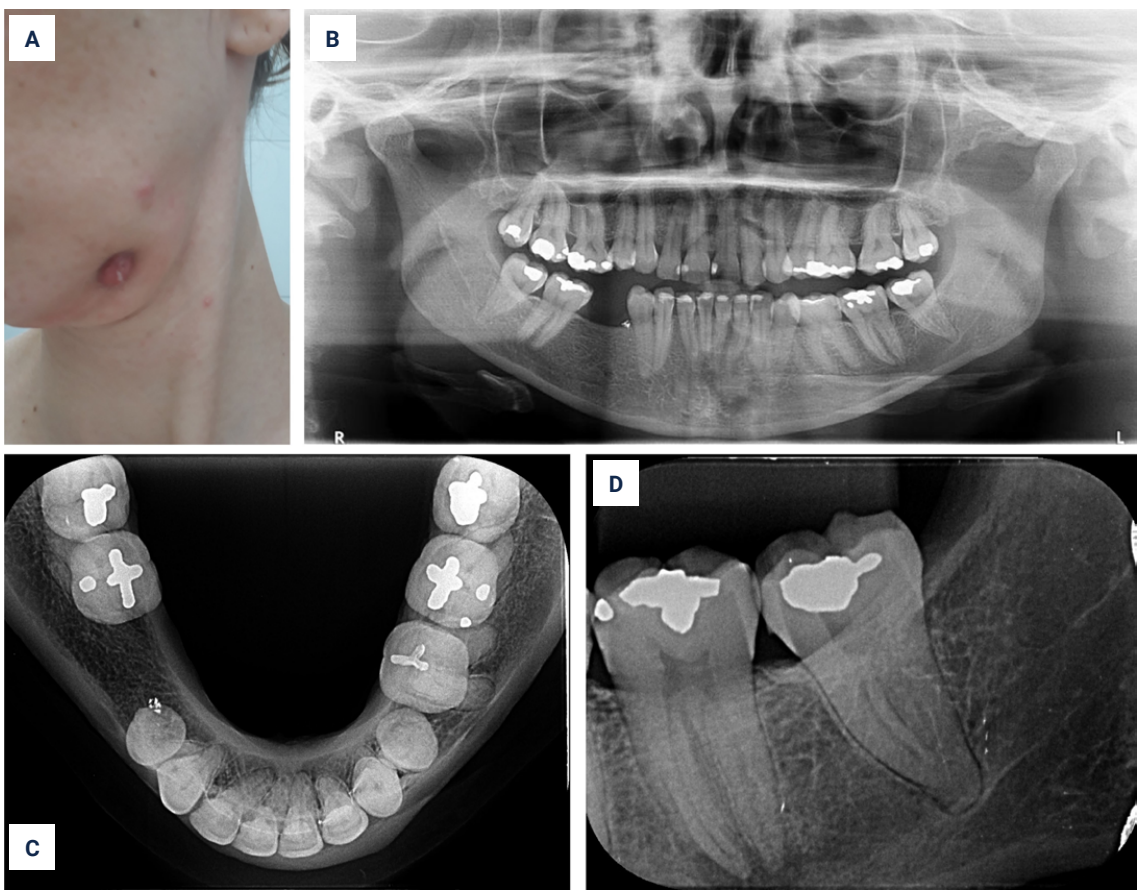

FIGURA 1 · (A) Fotografia extraoral da lesão cutânea na região submandibular esquerda no momento da chegada da paciente ao cirurgião-dentista Endodontista 2; (B) Radiografia panorâmica do momento que a paciente compareceu ao cirurgião-dentista Endodontista 1 revelando discreto espessamento do ligamento periodontal nas raízes da unidade 37; (C) Radiografia oclusal sem alterações da normalidade; (D) Radiografia periapical com imagem sugestiva de discreta lesão periapical da unidade 37. Tanto a radiografia oclusal quanto a periapical foram solicitadas pelo cirurgião-dentista especialista em cirurgia buco-maxilo-facial. 
na região do trígono submandibular esquerdo e durante 16 meses foi encaminhada a diversos profissionais de saúde sem resolução do caso.

O primeiro atendimento foi realizado por um cirurgião-dentista especialista em endodontia (CDE1) que, ao realizar exame extraoral, detectou um aumento de volume sem presença de fístula. No exame intraoral não foram encontradas alterações da normalidade. O laudo da radiografia panorâmica não trouxe informações que justificassem a alteração de volume apresentada pela paciente (Figura 1B).

O CDE1 ao não encontrar informações diagnósticas sugestivas de comorbidades orais associada à lesão extrabucal, encaminhou a paciente a um cirurgião bucomaxilo-facial. Este profissional por sua vez, avaliou a paciente e solicitou outros exames radiográficos: oclusal de mandíbula e periapicais das unidades dentárias mandibulares posteriores (Figuras 1C e 1D). Embora fosse possível detectar a presença de lesão perirradicular, o CDE1 não foi capaz de detectar informações substanciais nos exames e resolveu encaminhar ao médico cirurgião de cabeça e pescoço, que também avaliou a paciente e encaminhou ao oncologista. Este último, desconfiando de alguma anormalidade de origem não odontogênica, levantou a hipótese diagnóstica de sarcoma de partes moles, solicitando biopsia orientada por ultrassonografia com agulha grossa. Como resultado foi observado ausência de critérios histológicos de malignidade e pelas características encontradas houve suspeita de osteomielite.

A paciente foi reencaminhada ao primeiro profissional que a atendeu. $\mathrm{O}$ mesmo solicitou novamente exames de radiografias periapicais, panorâmica e posteriormente a tomografia computadorizada de feixe cônico (TCFC). O laudo do exame panorâmico e das radiografias periapicais apresentava imagem sugestiva de lesão periapical. A TCFC detectou perfuração da placa cortical vestibular da mandíbula com associação das raízes da 
unidade 37 que apresentava imagem hipodensa no periápice (Figura 2B, 2C, 2D e 3B).

Diante das novas averiguações o profissional encaminhou a paciente a outro profissional cirurgião-dentista especialista em endodontia (CDE2), que procedeu a avaliação da condição sistêmica durante a anamnese não identificando nenhuma alteração de importância clínica. Houve relato de alergias aos medicamentos: amoxicilina e dipirona sódica. No exame extraoral observa-se uma lesão cutânea não sensível e eritematosa, além de nodular-cística com secreção purulenta a palpação suave (Figura 3A). No exame intraoral o tecido mole apresentava-se normal, sem
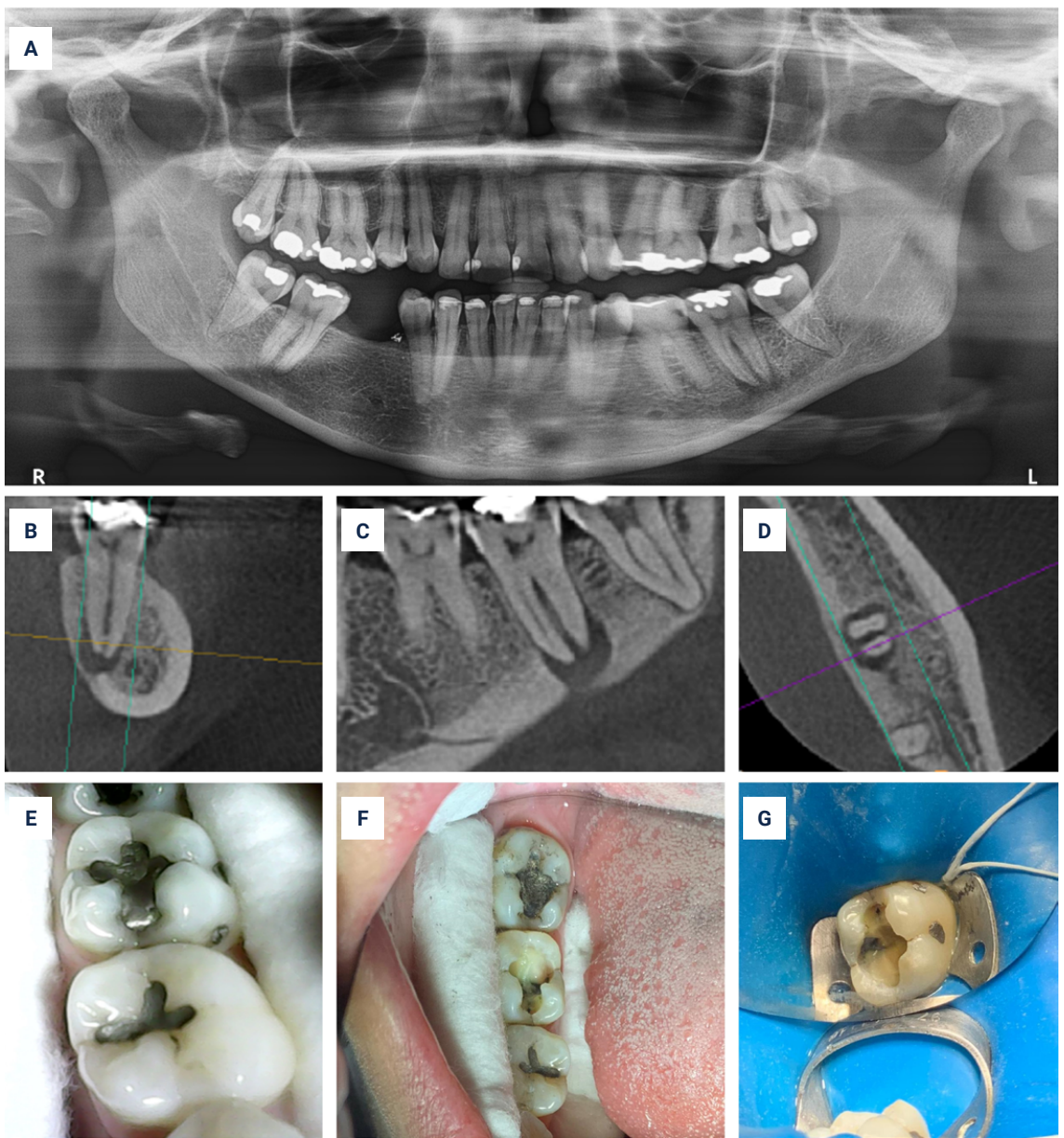

FIGURA 2 - (A) Radiografia panorâmica revelando imagem compatível com lesão periapical (13 meses após a 1 radiografia panorâmica); Cortes da tomografia computadorizada de feixe cônico demonstrando em (B) corte sagital, (C) Corte coronal com rompimento da tábua óssea vestibular da mandíbula e (D) corte axial. (E) fotografia intraoral da unidade dentária 37; (F) Fotografia intraoral após remoção da restauração de amalgama e com trinca a nível mesial; (G) Fotografia intraoral da unidade dentária 37 com isolamento do campo operatório. 
edema ou presença de fístula intraoral; não foi observada presença de lesões cariosas, inclusive, o dente suspeito (Unidade 37) apresentava restauração de amálgama satisfatória (Figura 2E).

O segundo molar inferior esquerdo apresentou sensibilidade à percussão horizontal e vertical. Não respondeu ao teste de sensibilidade pulpar (necrose pulpar). Não havia mobilidade nem bolsas periodontais. $\mathrm{Na}$ radiografia periapical constatou-se presença de lesão periapical. Os achados clínicos, radiológicos e patológicos levaram ao diagnóstico de fístula cutânea odontogênica associada à necrose pulpar da unidade dentária 37. Com base nessas descobertas, optou-se pela terapia endodôntica conservadora não cirúrgica, pois o dente envolvido era passível de restauração.

O procedimento endodôntico iniciou-se com a anestesia do bloqueio do nervo alveolar inferior com Lidocaína $2 \%$ com Epinefrina 1:100.000 (Alphacaine 2\%; DFL ${ }^{\oplus}$, Brasil). A restauração de amalgama foi removida, observando linhas sugestivas de trincas em esmalte na porção coronária. Logo depois, procedeu-se o acesso coronário e isolamento do campo operatório (Figura 2F e 2G). O comprimento de trabalho foi determinado usando um localizador foraminal eletrônico (Mine Apex locator ${ }^{\circledR}$, Sybronendo, USA) e foi confirmado radiograficamente.
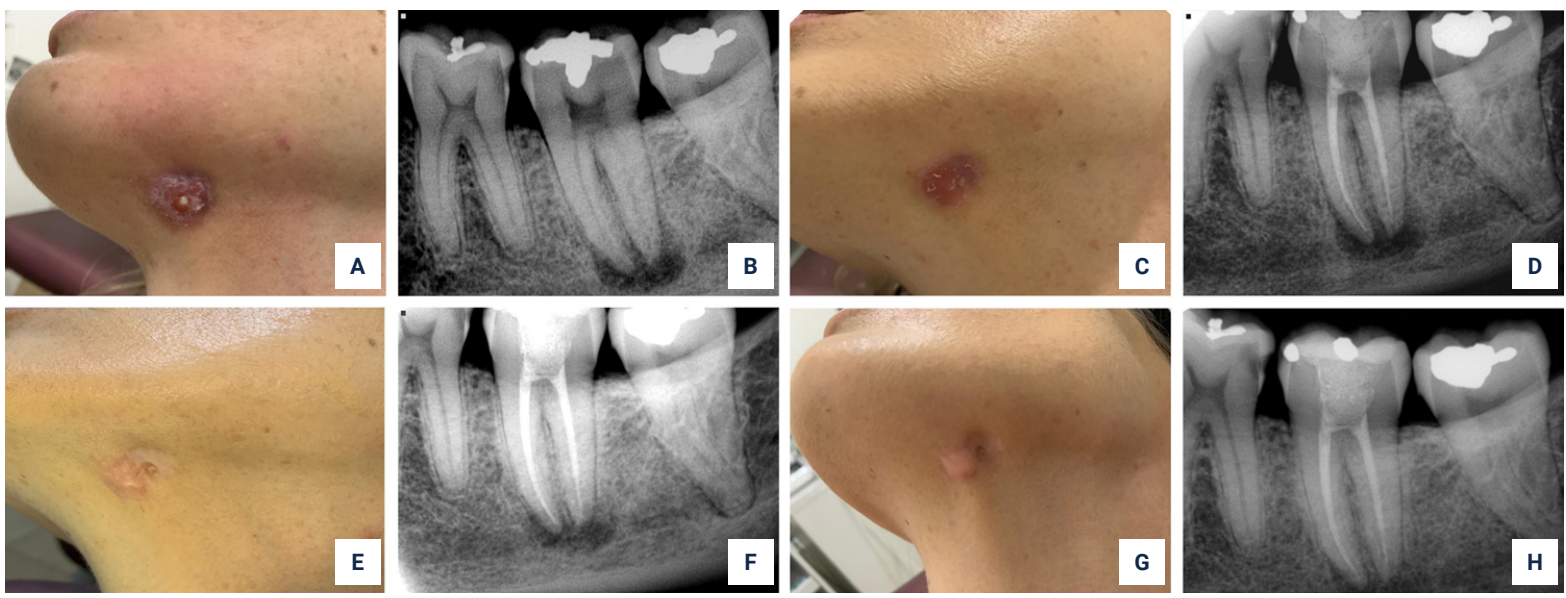

FIGURA 3 - (A) Fotografia inicial; (B) Radiografia periapical pré-operatória com imagem sugestiva de lesão periapical; (C) Lesão cutânea em remissão, 23 dias após obturação; (D) Radiografia periapical após obturação da unidade 37; (E) Lesão cutânea em remissão, 4 meses após a finalização do tratamento endodôntico e (F) Radiografia periapical 4 meses após a finalização do tratamento endodôntico, com remissão significativa da lesão e neoformação óssea; (G) Proservação de 6 meses, houve formação de uma reentrância em relação à pele que a circunda: (H) Imagem sugestiva de reparo ósseo periapical. 
O preparo dos canais foi realizado usando o instrumento Reciproc R25 (VDW, Munique, Alemanha), sendo os limites da instrumentação (CT) $22 \mathrm{~mm}$ nos canais mesiais e $20,5 \mathrm{~mm}$ no canal distal.

Como substância química auxiliar foi utilizado o gel de clorexidina a $2 \%$ (Farmácia de Marcela Dourada, Jequié, Brasil) e como solução irrigadora a solução salina, sendo a clorexidina ativada pelo instrumento XP-Endo finisher (FKG Dentaire SA ${ }^{\circledR}$, La Chaux-de-Fonds, Suíça). Ao final do preparo, foi removida a smear layer com auxílio do dispositivo EasyClean (Easy Equipamentos Odontológicos ${ }^{\circledR}$, Belo Horizonte, Brasil) e $5 \mathrm{~mL}$ de EDTA a 17\% (Farmácia de Marcela Dourada, Jequié, Brasil) por 3 minutos, seguido por uma irrigação final com $20 \mathrm{~mL}$ de solução salina estéril, e secagem dos condutos com pontas de papel absorvente estéreis. Os canais radiculares foram preenchidos com medicação intracanal à base de hidróxido de cálcio (Ultracal; Ultradent, South Jordan, EUA).

Para o selamento coronário colocou-se uma porção esférica de algodão na embocadura dos canais, coltosol (Vigodent, Rio de Janeiro, Brasil) cobrindo o algodão e finalizou com restauração provisória com cimento de ionômero de vidro (Maxxion R, $\mathrm{FGM}^{\circledR}$, Joinville, Brasil). Foi prescrito paracetamol para prevenção e controle da dor.

Após 23 dias, a paciente retornou para reavaliação da condição clínica. A mesma informou que não sentia mais incomodo na região e não apresentava sintomatologia. A área cutânea nodular apresentava sinais de cicatrização. Nesta consulta procedeu-se a obturação dos canais radiculares. Iniciou-se pela anestesia, isolamento absoluto e remoção completa do selamento coronário, além da irrigação copiosa dos canais radiculares com solução fisiológica. Foi feito reinstrumentação com o instrumento Reciproc R25, remoção de smear layer, secagem e obturação dos canais com a técnica de condensação lateral e com o cimento obturador sealer 26 (Dentsply Indústria e Comércio Ltda ${ }^{\circledR}$, Rio de Janeiro, Brasil). O selamento coronário foi realizado com 
coltosol na entrada dos condutos radiculares e restauração com cimento de ionômero de vidro.

Um mês após a obturação dos canais houve significativa resolução da fístula de origem odontogênica, estando a paciente assintomática. Não havia sensibilidade a pal pação ou a percussão. Procedendo-se com a restauração da unidade dental com resina composta (Filtek Z350 XT, ESPE ${ }^{\circledast}$, St. Paul, EUA) na cor A3,5.

Após 4 meses do tratamento endodôntico a paciente retornou para acompanhamento clínico. A mesma não apontou nenhuma sintomatologia dolorosa ou intercorrências. A avaliação clínica da lesão cutânea e da unidade dentária foram realizadas, não sendo detectada sensibilidade à palpação ou a percussão. Observou-se sinais de início de reparo na imagem da radiografia periapical (Figura 3E e 3F).

No acompanhamento de 6 meses após o tratamento endodôntico novo exame da tomografia computadorizada de feixe cônico foi realizado demonstrando imagem sugestiva de reparação do cortical óssea vestibular (Figura 4). A paciente encontrava-se assintomática e houve cura completa da fístula cutânea com formação de cicatriz inestética atrófica (Figura 3G e 3H). A mesma foi encaminhada ao serviço médico de dermatologia, uma vez que a cicatriz residual causava incomodo estético.

\section{Discussão}

O presente relato reporta uma fístula cutânea na região submandibular decorrente da necrose pulpar do segundo molar inferior
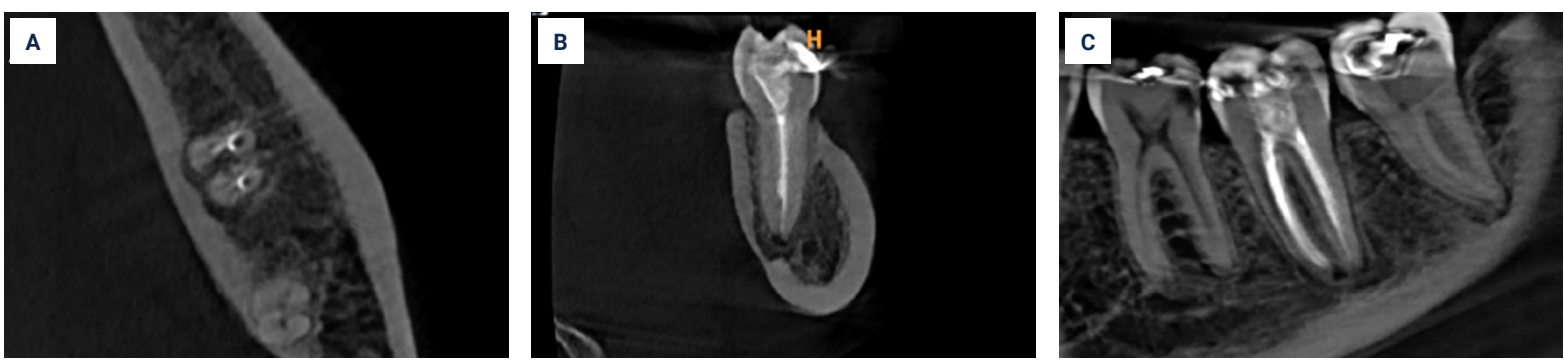

FIGURA 4 - Tomografia computadorizada de feixe cônico de proservação de 6 meses; (A) corte axial; (B) corte de 10 mm com imagem sugestiva de reparação da cortical óssea; (C) corte coronal com possível visualização da diminuição da lesão periapical. 
esquerdo. A paciente foi avaliada por 5 profissionais antes de um diagnóstico definitivo e conclusivo do caso (Figura 5). Em um estudo que investigou as características clínicas e epidemiológicas de 75 pacientes com diagnóstico de fístulas cutâneas odontogênicas foi observado que a lesão morfológica predominante era do tipo nódulo, em 39 casos (52\%) e em 74 deles (99\%) a localização era adjacente ao dente causador sendo os dentes mandibulares os mais afetados em $87 \%$ dos $\operatorname{casos}^{6}$. A relação dos ápices dentais posteriores com as inserções mandibulares dos músculos milo-hióideo e bucinador determinará se a drenagem será intraoral ou cutânea ${ }^{3}$. Na mandíbula, a perfuração óssea pode ocorrer acima da inserção do músculo, apresentando-se na mucosa anexa, no vestíbulo bucal ou no assoalho da boca; contudo se for abaixo dos anexos musculares, a fístula terá abertura extraoralmente, podendo aparecer na região mentual, região submentoniana ou submandibular. Neste presente relato a fístula se encontrava na região submandibular.

De forma geral, durante a anamnese, os pacientes que apresentam fístula cutânea não relatam sensações dolorosas, embora seja informado que há diferentes níveis de desconfortos antes do seu aparecimento ${ }^{4}$, como no presente relato de caso. Já na inspeção extraoral o examinador deve levar em consideração que

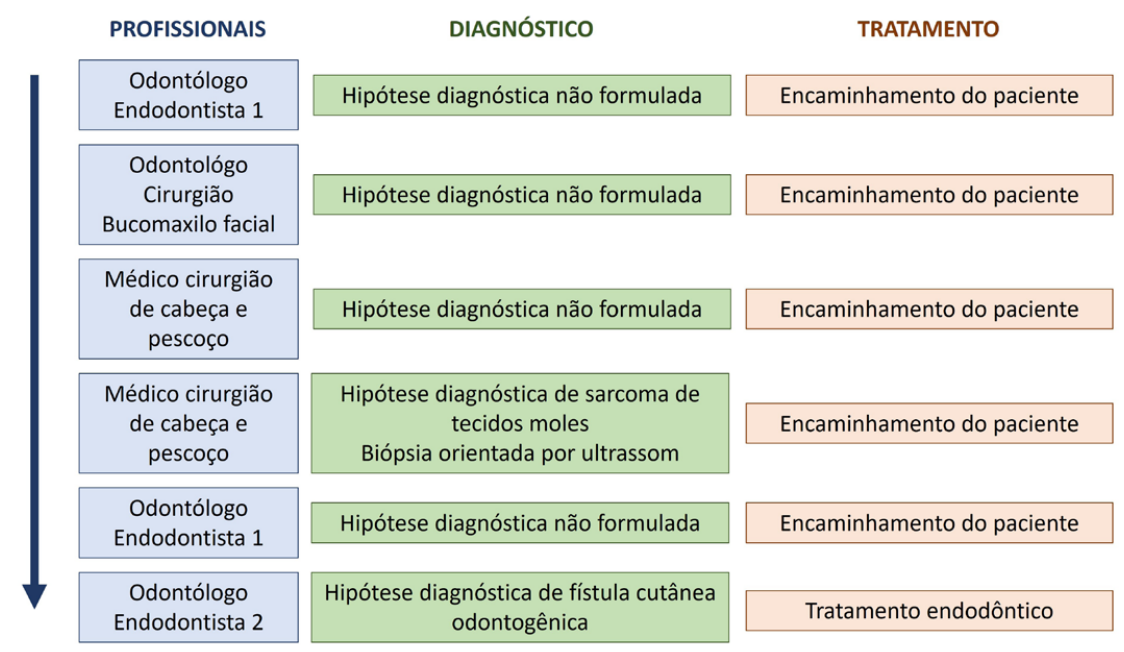

FIGURA 5 - Fluxograma de atendimento da paciente, com os diferentes profissionais que a atenderam, hipóteses diagnósticas formuladas e tratamentos estabelecidos. 
as manifestações cutâneas das fístulas odontogênicas possuem variabilidade morfológica, podendo apresentar uma ondulação, descoloração, ser um nódulo, goma, úlcera, lesão de drenagem, ou lesão nodulocística com supuração ${ }^{2,8}$. A fistula cutânea observada neste estudo apresentava um aspecto nodular cístico com supuração. No exame intraoral é importante estar atento à presença de cárie dentária, coroas protéticas, doença periodontal e restaurações infiltradas ou mal adaptadas, uma vez que estes dentes podem estar assintomáticos ${ }^{5}$. No presente caso não havia presença de lesões de cárie ou restaurações insatisfatórias, sendo observadas apenas linhas sugestivas de trincas próximas à restauração de amálgama presente na oclusal da coroa dentária, possíveis vias de penetração de microrganismos.

Apesar da paciente ter apresentado odontalgia prévia e ter relatado essa informação nas consultas aos profissionais, a origem dentária não foi considerada. A prática profissional é dependente do conhecimento teórico, da experiência, valores e habilidades que acabam por influenciar diferentemente na tomada de decisão, além de vícios de observação, aversão ao risco e tolerância quanto a incerteza, muitas vezes de forma inconsciente ${ }^{8}$. Apenas após descartada a origem dentária deve ser realizado o encaminhamento.

Neste relato a radiografia panorâmica inicial não apresentava imagens sugestivas de grandes lesões, havendo apenas um espessamento do ligamento periodontal na unidade 37 . No entanto, na radiografia periapical (Figura 1D) esse espessamento é mais nítido, sugerindo inclusive a presença de uma lesão periapical, negligenciada pelo CDE1. Em estado agudo de infecção não há sinais de alteração de imagem em exames complementares, sendo importante lançar mão de exames clínicos, como por exemplo os testes de sensibilidade pulpares. Essa informação pode ter sido negligenciada no primeiro momento da investigação. Somente após 1 ano de desenvolvimento da lesão periapical, com uma nova tomada radiográfica panorâmica, o 
aspecto radiolúcido circunscrito as raízes tornaram-se bastante nítidos. Deve-se lembrar que o exame radiográfico panorâmico pode ser útil para identificar alterações de normalidade e localização de dentes suspeitos, mas apresenta limitações, como não ser capaz de demonstrar a extensão exata das lesões ósseas e patologia dos tecidos moles associado a fístula, especialmente quando há suspeita de vários dentes ${ }^{3,5}$. Neste caso clínico a tomografia computadorizada de feixe cônico (TCFC) foi o exame complementar fundamental para determinar a relação do dente com radiolucidez circunscrita periapical e a lesão cutânea, a partir do acometimento da cortical mandibular. A TCFC permite a visualização da dentição, esqueleto maxilofacial e estruturas anatômicas circundantes em 3 dimensões sem sobreposições ${ }^{10}$.

Lee et al. ${ }^{2}$ (2016) verificaram que de 33 pacientes com fístulas de origem odontogênica, 27 foram diagnosticados inicialmente de forma incorreta $(81,8 \%)$. Os diagnósticos iniciais equivocados incluíram cisto epidérmico (24,2\%), furúnculo $(21,2 \%)$, micose subcutânea $(15,2 \%)$, carcinoma de células escamosas $(9,1 \%)$, carcinoma basocelular $(6,1 \%)$ e granuloma corporal $(6,1 \%)$. A etiologia dentária deve sempre ser considerada no diagnóstico diferencial de uma gama de patologias: osteomielite, tuberculose, actinomicose, esporotricose, micetoma, coccidioidomicose, granuloma piogênico, calázio, acnes, neoplasias (tal como o carcinoma de células escamosas), fístulas de origem glandular, cisto infectado e outras infecções locais da pele (por exemplo, carbúnculos e cistos epidermóides infectados). Todas essas patologias podem ter características variáveis e pontos semelhantes $^{3,4,6}$. Assim, um dente infectado deve ser suspeito como a etiologia primária das fístulas cutâneas, no entanto este diagnóstico pode ser facilmente esquecido por médicos, já que não estão familiarizados com as origens dentárias, mas não deveria ser por cirurgiões-dentistas ${ }^{1,10}$.

Neste relato, quando a paciente foi encaminhada ao oncologista, o mesmo realizou a biopsia com a hipótese diagnóstica de 
possível sarcoma de partes moles. Devido à inespecificidade e ao mesmo tempo a mimetização da lesão, doenças malignas, como câncer gengival, osteossarcoma, sarcoma de Ewing e tumor célula gigante, podem também fazer parte das patologias a serem consideradas na determinação do diagnóstico diferencial $^{1,11}$. Quando um profissional de saúde cita a necessidade de realização de biopsia para diagnosticar alguma lesão, o paciente transita entre a possibilidade de ser algo simples de se tratar até ao desenvolvimento de pensamentos negativos ao buscar informações sobre sua doença. O imaginário alimenta o sofrimento psicológico que está relacionado aos sintomas de ansiedade, depressão, agitação, entre outros. Além disso, o diagnóstico quando incorreto pode causar inadequação do tratamento que, por sua vez, aumenta a cronicidade da lesão ou melhora temporariamente os sintomas. Excisões desnecessárias podem afetar a estética ou levar a deformidades faciais ${ }^{1,5}$.

A colaboração interprofissional melhora os resultados em saúde, isto porque a gama de patologias do diagnóstico diferencial pode levar ao tratamento equivocado, mas com trabalho colaborativo as práticas e experiências profissionais se complementam. Existe uma tendência de cada profissão atuar isoladamente com uma barreira para a comunicação. A falta de tempo para aprender uns com os outros em trabalhos colaborativos pode ser uma justificativa, assim como a existência de barreiras estruturais, estereótipos sobre outras categoriais profissionais e competição. Um profissional não consegue dar conta de todas as dimensões do cuidado e acaba por oferecer um tratamento fragmentado. Com um diálogo coeso, a construção coletiva acaba por promover um projeto terapêutico integral e singular de melhor qualidade e com maior capacidade de respostas aos problemas e às necessidades de saúde ${ }^{12,13}$.

Neste caso a cura permanente foi obtida após tratamento dentário adequado, através da terapia endodôntica da unidade 37 e tratamento restaurador; entretanto, para outros casos a extração 
pode ser indicada ${ }^{8}$. Considerando sempre que um dente deve ser extraído apenas quando se apresenta não restaurável, pois a manutenção dos dentes naturais preserva a função, a integridade do arco, a estabilidade oclusal e a estética, além de eliminar a necessidade de procedimentos onerosos ${ }^{14}$. As ondulações e hiperpigmentação da pele geralmente diminuem lentamente e às vezes, permanece uma cicatriz ou uma pequena depressão. No presente relato, após seis meses da conclusão do tratamento foi observado que o aspecto crostoso e eritematoso desapareceu e que a lesão cicatrizou sem recorrência, entretanto houve necessidade de encaminhamento a um especialista em dermatologia para avaliar a cicatriz inestética desenvolvida.

\section{Conclusão}

Este relato de caso enfatiza a necessidade de que profissionais de saúde levem em consideração a origem dentária no diagnóstico diferencial da fístula cutânea. Os cirurgiões-dentistas devem realizar uma averiguação da história pregressa, além de praticar uma escuta ativa do paciente, pois assim será possível extrair informações preciosas para o diagnóstico clínico. Os exames devem ser minuciosos, acompanhados de investigações adicionais apropriadas. Os médicos e cirurgiões-dentistas devem realizar trabalho colaborativo em busca de solucionar casos como o aqui relatado, uma vez que é um diagnóstico desafiador e, por isso, deve ser considerada a origem odontogênica no diagnóstico diferencial, sendo imperativo que o cirurgião-dentista descarte a hipótese de origem dentária da lesão cutânea antes de realizar encaminhamentos a outros profissionais.

\section{Referências}

1 - Al-Obaida MI, Al-Madi EM. Cutaneous draining sinus tract of odontogenic origin: A case of chronic misdiagnosis. Saudi Med J. 2019; 40(3):292-297.

2 - Lee E-Y, Kang J-Y, Kim K-W, Choi KH, Yoon TY, Lee JY. Clinical characteristics of odontogenic cutaneous fistulas. Ann Dermatol. 2016; 28(4):417. 
3- Sodnom-Ish B, Eo MY, Kim SM. An accurate diagnosis of odontogenic cutaneous sinus tract by different computed tomography unit setting. J Korean Assoc Oral Maxillofac Surg. 2021;47(1):51-56.

4 - Shemesh A, Hadad A, Azizi H, Lvovsky A, Ben Itzhak J, Solomonov M. Cone-beam computed tomography as a noninvasive assistance tool for oral cutaneous sinus tract diagnosis: A case series. J Endod. 2019; 45(7):950-956.

5 - Zemmouri Y, Chbicheb S. Esthetic improvement of a cutaneous sinus tract of odontogenic origin. Pan Afr Med J. 2020; 30(37):204.

6 - Guevara-Gutiérrez E, Riera-Leal L, Gómez-Martínez M, AmezcuaRosas G, Chávez-Vaca CL, Tlacuilo-Parra A. Odontogenic cutaneous fistulas: clinical and epidemiologic characteristics of 75 cases. Int J Dermatol. 2015; 54(1):50-55.

7 - Janev E, Redzep E. Managing the cutaneous sinus tract of dental origine. Open Access Maced J Med Sci. 2016; 4(3):489-492.

8 - Chang LS. Common pitfall of plastic surgeon for diagnosing cutaneous odontogenic sinus. Arch Craniofac Surg. 2018; 19(4):291-295.

9 - Nobre MRC, Bernardo WM, Jatene FB. A prática clínica baseada em evidências. Parte I: questões clínicas bem construídas. Rev Assoc Med Bras. 2003; 49(4):445-449.

10 - Baba A, Okuyama Y, Shibui T, Ojiri H. Odontogenic cutaneous fistula mimicking malignancy. Clin Case Rep. 2017; 5(5):723-724.

11 - Carvalho AA, Costa AC, Miranda CSS, et al. Acompanhamento psicológico de um paciente com câncer de boca no ambulatório de diagnóstico estomatológico do Sudoeste Goiano (ADESGO). Saúde em Revista. 2020;20(52):12.

12 - Oliveira MJS, Souza AD, Calvetti PÜ, Filippin LI. A escuta ativa como estratégia de humanização da assistência em saúde. SDH. 2018; 6(2):33.

13 - Forte FDS, Morais HGF, Rodrigues SAG, et al. Educação interprofissional e o programa de educação pelo trabalho para a saúde/ Rede Cegonha: potencializando mudanças na formação acadêmica. Interface (Botucatu). 2016; 20(58):787-796.

14 - Gharechahi M, Dastmalchi P. Cutaneous sinus tract from mandibular second molar with C-shaped canal system and improper former root canal treatment: A case report. Bull Tokyo Dent Coll. 2016; 57(3):183187. 


\title{
Odontogenic cutaneous fistula: report of a clinical case after multiple misdiagnoses
}

\begin{abstract}
Cutaneous fistula of odontogenic origin is related to a chronic infection and when misdiagnosed by physicians and/or dentists, it can cause esthetic alteration and psychological disorders to the patient. This case report describes the correct diagnosis and treatment of a patient who was previously referred to different health professionals, including undergoing a biopsy after incorrect diagnostic hypotheses. After clinical evaluation and periapical radiographic examinations and cone beam computed tomography, requested by an endodontist, the case was properly diagnosed, and a treatment plan proposed. Non-surgical endodontic treatment was performed, providing resolution of the fistula in a short period of time. The present clinical case reinforces the need to perform the differential diagnosis of pathologies associated with cutaneous fistulae occurring in the facial or cervical region, and the importance of interprofessional collaboration, including considering the odontogenic etiology.
\end{abstract}

KEYWORDS: Dental Pulp Necrosis; Cutaneous Fistula, Diagnosis.

\section{Como citar este artigo}

Pereira JS, Andrade-Júnior CV, Silva EJNL. Fístula cutânea odontogênica: relato de um caso clínico após múltiplos diagnósticos errôneos. Rev Odontol Bras Central 2021; 30(89):372-386. DOI: 10.36065/robrac.v30i89.1549 